\title{
Predictors of poor glycemic control among patients with type 2 diabetes on follow-up care at a tertiary healthcare setting in Ethiopia
}

Gebre Teklemariam Demoz ${ }^{1 *}$, Alem Gebremariam² ${ }^{2}$ Helen Yifter ${ }^{3}$, Minyahil Alebachew $^{4}$, Yirga Legesse Niriayo ${ }^{5}$, Gebremicheal Gebreslassie", Gebremariam Woldu' ${ }^{1}$, Degena Bahrey ${ }^{6}$ and Workineh Shibeshi ${ }^{4}$

\begin{abstract}
Objective: Contemporary clinical guidelines endorsed that glycemic control is the ultimate goal in the management patients with diabetes. The aim of this study was to assess the prevalence of glycemic control and to identify predictors of poor glycemic control in patients with type 2 diabetes (T2D). A cross-sectional study was conducted among systematically selected 357 diabetic patients. Data were collected through direct patients' interviews and medical chart review. Binary logistic regression analyses were performed and analyzed using SPSS version 22.0.

Results: Participants' mean age was ( \pm SD) $56.1 \pm 11.6$ years. Nearly four in five $(77.9 \%)$ of the participants had comorbidities, mainly of hypertension, and $60.2 \%$ had diabetic complications, mainly diabetes neuropathy. Poor glycemic control was found in $68.3 \%$ of the participants with a mean ( \pm SD) FBG of $174.1 \pm 48.9 \mathrm{mg} / \mathrm{dL}$. Being female gender, having greater body mass index and low medication adherence was significantly associated with poor glycemic control. In conclusion, the overall aspects of glycemic control level of patients were far from the standards. Being female, greater body mass index and poor medication adherence were predictors of poor glycemic control. In response to this finding, an aggressive intervention that targets in improving the glycemic control is required.
\end{abstract}

Keywords: Type 2 diabetes, Fasting blood glucose, Glycemic control, Predictors, Ethiopia

\section{Introduction}

Diabetes is a chronic metabolic disorder characterized by persistent hyperglycemia due to a deficiency in insulin secretion, insulin action or both [1-3]. Diabetes is one of the leading health problems of this century. The prevalence of type 2 diabetes (T2D) is increasing over time. Likewise, the prevalence of people living with diabetes in Ethiopia is substantially increased from time to time. Thus, increased from $3.8 \%$ in 2014 to $5.2 \%$ in 2017 [3-5].

Glycemic control is the ultimate goal of management of diabetes [2,6]. Adequate glycemic control helps to reduce or delay the burden of diabetes complications [7].

\footnotetext{
*Correspondence: gebretekl@gmail.com

${ }^{1}$ School of Pharmacy, Aksum University, Po.Box: 298, Aksum, Ethiopia

Full list of author information is available at the end of the article
}

According to the International Diabetes Federation and the American Diabetes Association guidelines, glycated hemoglobin (HgA1c) value is the most recommended monitoring parameter for appropriate glycemic control status. Thus, the value of $\mathrm{HgAlc}$ within the last 3 months is indicators of patients' glycemic control [2, 8]. Many studies reveal an association between $\mathrm{HgAlc}$ values and diabetes complications. Reducing HgA1c values significantly decreases diabetes complications and the overall death from diabetes [9-11]. Thus, early and adequate glycemic control improves macrovascular outcomes [12] and diabetes complications [13-15].

Achieving optimal glycemic level may not be an easy task. It depends on the type of treatment received patients' adherence and comorbidities [2,3]. Likewise, risk factors, obesity, biological and psychosocial factors 
are responsible for differences in glycemic control [16]. Limited data are currently available that evaluate the relationship of glycemic control with lifestyle, clinical characteristics, and treatment pattern. Hence, the primary purpose of this study was to identify predictors of glycemic control status in T2D patients.

\section{Main text}

Methods

\section{Study design and study setting}

A hospital-based cross-sectional study design was conducted from August 2017 through July 2018 at Tikur Anbessa Specialized Hospital (TASH). This hospital is the largest public referral and teaching hospital in Ethiopia which is affiliated to Addis Ababa University. The hospital has about 800 beds and is in the provision of complicated diagnostic and treatment services for about 500,000 patients a year.

\section{Study population}

During the 3 months' study period, about 2160 diabetes patients were expected to visit the diabetes clinic (Fig. 1). We calculated the minimum sample size of participants using a single population formula, by taking $50 \%$ of population and found 384, adding $10 \%$ contingency $=423$. Out of these, 357 patients were selected using systematic sampling technique. The inclusion criteria were confirmed cases of T2D aged 18 years and above, ambulatory patients with T2D who were taking at least one antidiabetic drug, patients with T2D who had regular follow-up in the diabetes clinic for at least 1 year. Data were collected through patient interview using structured questionnaire designed for this study. The questionnaire was included questions about sociodemographic details, (includes as gender, age, marital status, level of education and employment status), questions about the patients' clinical characteristics (includes diabetes complications, comorbidities and duration of diabetes) and questions about the patients' lifestyle details (includes physical activities, alcohol use, smoking and dietary plan). Variables extracted from medical chart were medications taken by the patients for diabetes and other comorbidities, laboratory values for diabetes and related medical conditions. Anthropometric measurement values; includes height and weight, body mass index (BMI) and waist circumference (WC) were obtained at the time of interview.

\section{Data processing and analysis}

Data were entered and analyzed using EpiData Manager Version 4.0.2.00 (EpiData Association, Denmark) [17] and SPSS version 22.0 (SSPS Inc., Chicago, Illinois,

An estimated number of patients with diabetes expected to visit the Diabetes center during the study period $(\mathrm{N} \approx 2160)$

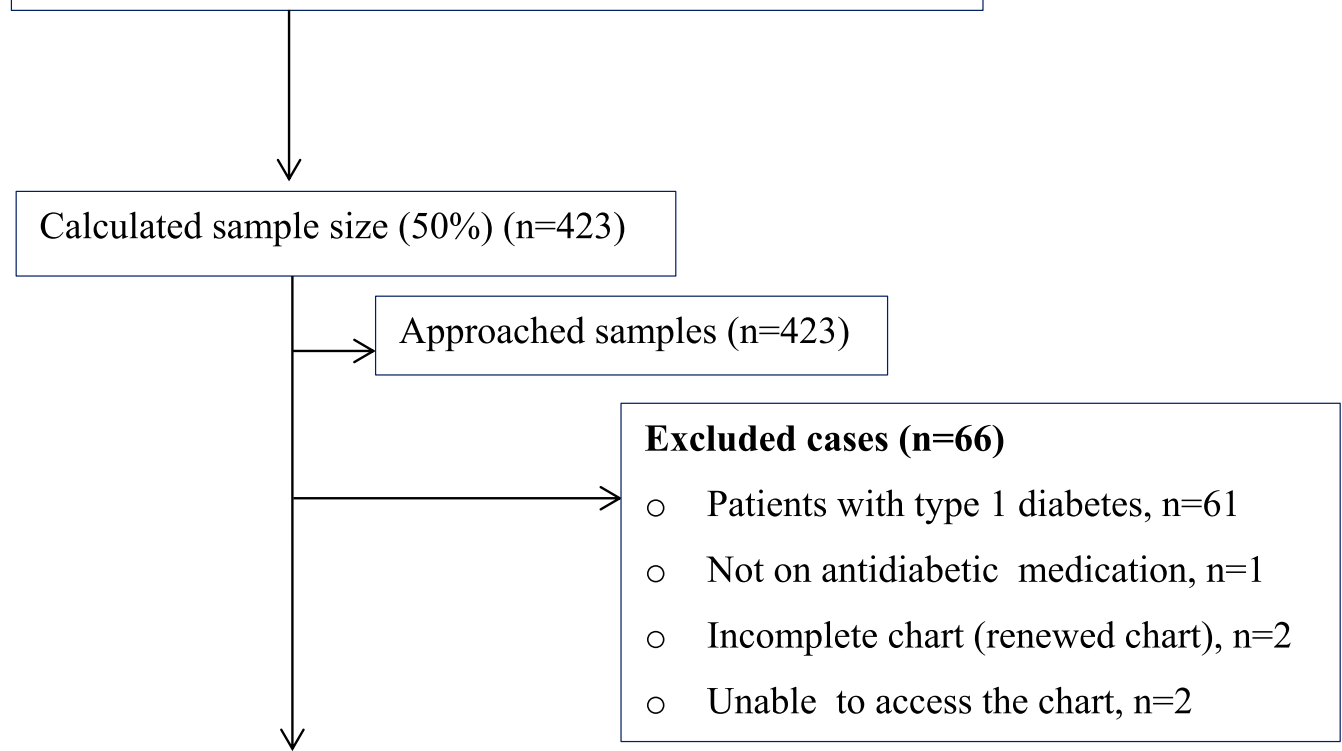

Final sample in analysis $(n=357)$

Fig. 1 Summary of study participants recruiting flow chart 
USA), respectively. Descriptive statistics and binary logistic regression model was used to investigate predictors of poor glycemic control and presented using Odds Ratios (ORs) with its 95\% confidence intervals (CIs). Statistical significance was considered at p-value $<0.05$.

\section{Definitions}

Adequate glycemic control it was defined as average fasting blood glucose measurement between 70 and $130 \mathrm{mg} / \mathrm{dL}$ or $\mathrm{HbA}_{1 \mathrm{c}}<7 \%$.

Poor glycemic control it was defined as patients whose average blood glucose measurements of the three consecutive visits was above 130 or below $70 \mathrm{mg} / \mathrm{dL}$ or $\mathrm{HbA}_{1 \mathrm{c}}>7 \%[2,3,8]$.

\section{Results}

Sociodemographic and clinical characteristics

A total of 357 study participants were included in the study. The mean $( \pm S D)$ age of the study participants was $56 \pm 11$ years. More than half, 189 (52.9\%) of the participants were females (Table 1). The clinical characteristics of patients with T2D are described in Table 1. The mean duration of the diabetes disease since diagnosis was $11.64 \pm 6.95$ years. Comorbidity in these study participants was considerable, 278 (77.9\%). The most common comorbidity was hypertension, 188 (65.5\%), followed by dyslipidemia 171 (60.9\%) and ischemic heart disease 37 (13.1\%). Moreover, 215 (60.2\%) participants had developed at least one chronic diabetes complications. Furthermore, more participants $(60.2 \%)$ with poor glycemic control had one or more diabetes complication. Diabetic

Table 1 Sociodemographic and clinical characteristics of T2D patients on follow-up at diabetes center, Ethiopia, 2018

\begin{tabular}{|c|c|c|c|c|c|}
\hline \multirow[t]{2}{*}{ Category } & \multirow[t]{2}{*}{ Subcategory } & \multicolumn{2}{|c|}{ Glycemic control } & \multirow[t]{2}{*}{ Total (\%) } & \multirow[t]{2}{*}{ p-value } \\
\hline & & Poor & Good & & \\
\hline \multirow[t]{2}{*}{ Sex } & Male & $74(30.2)$ & $94(83.2)$ & $168(47.1)$ & \\
\hline & Female & $170(69.8)$ & $19(16.8)$ & $189(52.9)$ & 0.012 \\
\hline \multirow[t]{3}{*}{ Age group } & $18-40$ & $14(5.7)$ & $8(7.1)$ & $22(6.2)$ & 0.12 \\
\hline & $41-60$ & $134(54.9)$ & $54(47.8)$ & $188(52.7)$ & \\
\hline & $>60$ & $96(39.3)$ & $51(45.1)$ & $147(41.7)$ & \\
\hline \multirow[t]{2}{*}{ Marital status } & Never married & $8(3.3)$ & $5(4.4)$ & $13(3.6)$ & 0.59 \\
\hline & Ever married & $236(96.7)$ & $108(95.6)$ & $344(96.4)$ & \\
\hline \multirow[t]{2}{*}{ Residence } & Urban & $206(84.4)$ & $98(86.7)$ & $304(85.2)$ & 0.57 \\
\hline & Rural & $38(15.6)$ & $15(13.3)$ & $53(14.8)$ & \\
\hline \multirow[t]{4}{*}{ Education } & No formal education & $33(13.5)$ & $17(15.0)$ & $50(14.0)$ & 0.52 \\
\hline & Primary $(1-8)$ & $47(19.3)$ & $16(14.2)$ & $63(17.6)$ & \\
\hline & Secondary (9-12) & $66(27.0)$ & $37(32.7)$ & $103(28.9)$ & \\
\hline & Tertiary (graduates) & $98(40.2)$ & $43(38.1)$ & $141(39.5)$ & \\
\hline \multirow[t]{2}{*}{ Employment } & Employed & $135(55.3)$ & $66(58.4)$ & $201(56.3)$ & 0.59 \\
\hline & Unemployed & $109(44.7)$ & $47(41.6)$ & $156(43.7)$ & \\
\hline Duration of diabetes & Mean $( \pm S D)$ & $13.01 \pm 3.11$ & $10.24 \pm 2.13$ & $11.64 \pm 6.95$ & 0.051 \\
\hline \multirow[t]{2}{*}{ Presence of comorbidities } & Yes & $195(79.9)$ & $83(73.5)$ & $278(77.9)$ & 0.115 \\
\hline & No & $49(20.1)$ & $30(26.5)$ & $79(22.1)$ & \\
\hline \multirow[t]{4}{*}{ Types of co morbidities } & Hypertension & $130(53.3)$ & $58(51.3)$ & $188(65.5)$ & 0.381 \\
\hline & Dyslipidemia & $123(50.4)$ & $48(42.5)$ & $171(60.9)$ & 0.222 \\
\hline & $\mathrm{IHD}$ & $27(11.1)$ & $10(8.8)$ & $37(13.1)$ & 0.414 \\
\hline & Others $^{a}$ & $32(13.1)$ & $18(15.9)$ & $50(17.7)$ & 0.201 \\
\hline \multirow[t]{2}{*}{ Diabetes complications } & Yes & $193(79.1)$ & $22(19.5)$ & $215(60.2)$ & 0.018 \\
\hline & No & $51(20.9)$ & $91(80.5)$ & $142(39.8)$ & \\
\hline \multirow[t]{3}{*}{ Types of complications } & Neuropathy & $143(58.6)$ & $24(21.2)$ & $167(46.8)$ & 0.036 \\
\hline & Nephropathy & $62(25.4)$ & $6(5.3)$ & $68(19.1)$ & 0.374 \\
\hline & Retinopathy & $45(18.4)$ & $5(4.4)$ & $50(14.0)$ & 0.262 \\
\hline $\mathrm{FBG}, \mathrm{mg} / \mathrm{dL}$ & Mean $( \pm S D)$ & $186.8 \pm 47.4$ & $146.6 \pm 39.9$ & $174.10 \pm 48.9$ & $<0.001$ \\
\hline BMI $\left(\mathrm{kg} / \mathrm{m}^{2}\right)$ & Mean $( \pm S D)$ & $29.4 \pm 6.1$ & $24.9 \pm 4.5$ & $27.15 \pm 4.6$ & 0.217 \\
\hline
\end{tabular}

a Thyroid disorders, peptic ulcer disease, asthmatic 
neuropathy was the most (46.8\%) commonly reported diabetes complications.

Moreover, the mean $( \pm \mathrm{SD})$ BMI of participants was $27.15 \pm 4.6 \mathrm{~kg} / \mathrm{m}^{2}$. Of these, the majority $(76 \%)$ of the obese $\left(>30 \mathrm{~kg} / \mathrm{m}^{2}\right)$ participants were females. However, more than $70 \%$ of the participants have been reported as they are adherent to regular physical activity.

\section{Prescribed medication profiles}

More than half (53.8\%) of participants were on oral glucose-lowering drugs (OGLD) alone (with no insulin as a component of their drug therapy), followed by OGLD plus insulin (27.7\%) and insulin alone, with no OGLD (18.5\%). The most frequently prescribed antidiabetic agent was metformin (78.4\%) (Additional file 1). In addition, glycated hemoglobin (HgA1c) is the gold standard for monitoring blood sugar, but in our clinic very few $(14.8 \%)$ of the participants had HgAlc results. The mean of FBG level for the last three consecutive visits was $174.1 \pm 48.9 \mathrm{mg} / \mathrm{dL}$. Of the studied participants, $68.3 \%$ of participants were found to have poor glycemic control.

\section{Predictors of poor glycemic control}

As illustrated in Table 2, the predictors statistically significant with poor glycemic control in the multivariable analysis were being female gender, BMI $\left(>30 \mathrm{~kg} / \mathrm{m}^{2}\right)$ and poor medication adherence. From the AOR, being female gender $(\mathrm{AOR}=1.59,95 \% \mathrm{CI} 1.20-2.38, \mathrm{p}=0.041)$ was positively associated to have poor glycemic control. Moreover, the odds of poor glycemic control among participants who had obese was increased by more than three times $(\mathrm{AOR}=3.51,95 \% \mathrm{CI} 1.82-4.01, \mathrm{p}=0.027)$ compared to participants with normal body weight. On the other hand, the odds of poor glycemic control among patients who had poor adherence to their medication were five times ( $\mathrm{AOR}=5.10,95 \%$ CI 1.18-6.55,

Table 2 Predictors for poor glycemic control in patients with T2D on follow up at diabetes center, Ethiopia, 2018

\begin{tabular}{|c|c|c|c|c|c|c|}
\hline \multirow[t]{2}{*}{ Category } & \multirow[t]{2}{*}{ Subcategory } & \multicolumn{2}{|c|}{ Glycemic control level } & \multirow[t]{2}{*}{ COR $(95 \%$ of $\mathrm{Cl})$} & \multirow[t]{2}{*}{ AOR $(95 \%$ of $\mathrm{Cl})$} & \multirow[t]{2}{*}{ p-value } \\
\hline & & Poor & Good & & & \\
\hline \multirow[t]{2}{*}{ Sex } & Male & $74(44.0)$ & $94(56.0)$ & 1 & 1 & \\
\hline & Female & $170(89.9)$ & $19(10.1)$ & $1.25(1.8-2.21)$ & $1.59(1.20-2.38)$ & $0.041^{* *}$ \\
\hline Age & Mean $( \pm S D)$ & $56 \pm 11$ & $57 \pm 12$ & $2.11(0.81-1.75)$ & $1.57(1.11-2.31)$ & 0.146 \\
\hline \multirow[t]{2}{*}{ Marital status } & Never married & $8(61.5)$ & $5(38.5)$ & $0.89(0.55-1.47)$ & $0.93(0.81-1.35)$ & 0.593 \\
\hline & Ever married & $236(68.6)$ & $108(31.4)$ & 1 & 1 & \\
\hline \multirow[t]{4}{*}{ Education } & No formal education & $33(66.0)$ & $17(34.0)$ & $2.81(0.21-0.89)^{*}$ & $1.59(0.37-1.09)$ & 0.061 \\
\hline & Primary (1-8) & $47(74.6)$ & $16(25.4)$ & $2.51(0.31-1.53)$ & $2.10(0.75-1.77)$ & 0.089 \\
\hline & Secondary (9-12) & $66(64.1)$ & $37(35.9)$ & $1.22(0.51-1.28)$ & $1.11(0.55-1.31)$ & 0.102 \\
\hline & Tertiary (graduates) & $98(69.5)$ & $43(30.5)$ & 1 & 1 & \\
\hline \multirow[t]{2}{*}{ Exercise } & No & $81(77.1)$ & $24(22.9)$ & $3.71(0.24-0.87)^{*}$ & $2.92(0.78-1.10)$ & 0.092 \\
\hline & Yes & $163(64.7)$ & $89(35.3)$ & 1 & 1 & \\
\hline \multirow[t]{2}{*}{ Complications } & No & $51(35.9)$ & $91(64.1)$ & 1 & 1 & \\
\hline & Yes & $193(89.9)$ & $22(10.1)$ & $2.20(0.44-.88)^{*}$ & $2.0(0.69-1.06)$ & 0.074 \\
\hline \multirow[t]{3}{*}{$\mathrm{BMI}\left(\mathrm{kg} / \mathrm{m}^{2}\right)$} & Normal & $15(45.5)$ & $18(54.5)$ & 1 & 1 & \\
\hline & Overweight & $94(64.8)$ & $51(35.2)$ & $1.49(0.23-0.91)^{*}$ & $1.68(1.01-2.55)$ & 0.061 \\
\hline & Obese & $135(75.4)$ & $44(24.6)$ & $2.88(1.27-2.86)$ & $3.51(1.82-4.01)$ & $0.027^{* *}$ \\
\hline \multirow[t]{2}{*}{ Lipid control } & Good & $45(35.4)$ & $82(64.6)$ & 1 & 1 & \\
\hline & Poor & $199(86.5)$ & $31(13.5)$ & $2.35(0.29-0.83)^{*}$ & $2.13(0.57-1.34)$ & 0.088 \\
\hline \multirow[t]{2}{*}{ BP control } & Controlled & $43(35.5)$ & $78(64.5)$ & 1 & 1 & \\
\hline & Uncontrolled & $201(85.2)$ & 35 (14.8) & $3.41(0.61-1.33)$ & $4.51(0.89-1.94)$ & 0.112 \\
\hline \multirow[t]{3}{*}{ Antidiabetics } & Oral alone & $13(1.4)$ & $55(28.6)$ & 1 & 1 & \\
\hline & Oral + insulin & $71(71.7)$ & $28(28.3)$ & $1.11(0.29-0.97)^{*}$ & $1.81(0.59-1.64)$ & 0.067 \\
\hline & Insulin & $36(54.5)$ & $30(45.5)$ & $0.85(0.66-1.20)$ & $0.96(0.79-1.38)$ & 0.091 \\
\hline \multirow[t]{2}{*}{ Adherence } & Low adherence & $102(65.0)$ & $55(35.0)$ & $4.59(1.13-4.58)$ & $5.10(1.18-6.55)$ & $0.001^{*}$ \\
\hline & High adherence & $65(73.0)$ & $24(27.0)$ & 1 & 1 & \\
\hline \multirow[t]{2}{*}{ Dietary plan } & Poor adherence & $192(91.0)$ & $19(9.0)$ & $2.91(0.31-0.85)^{*}$ & $3.44(0.71-1.55)$ & 0.098 \\
\hline & Good adherence & $62(39.7)$ & $94(60.3)$ & 1 & 1 & \\
\hline
\end{tabular}

COR crude odds ratio, $A O R$ adjusted odds ratio, SD standard deviation, $B M I$ body mass index, $B P$ blood pressure

* Indicates $\mathrm{p} \leq 0.05$ in the univariate and ${ }^{* *} \leq 0.05$ in the multivariate analysis 
$\mathrm{p}=0.001)$ more than patients who had high adherence to their medication.

\section{Discussion}

From this study, we found that more than two-thirds $(68.9 \%)$ of the patients had poor glycemic control. This proportion is comparable with studies conducted (70.9\%) by Kassahun et al. [18] and $71.9 \%$ by Hailu et al. [19]. However, this finding was lower than that found from other Ethiopian studies that reported as $81.7 \%$ by Angamo et al. [20]. In addition, this percentage was higher than the percentages found in Ethiopian (61.5\%) [21] and Jordanian $(60.8 \%)$ patients with T2D [10]. This level of clinical outcome may require a comprehensive approach to working with patients to achieve the intended glycemic level.

Furthermore, more than half (53.8\%) of participants were on oral OGLD alone (with no insulin as a component of their drug therapy). This percentage was consistent with the finding (54.4\%) reported by Weng et al. [22]. The most frequently prescribed antidiabetic agent used as monotherapy and/or combination therapy with at least one other oral and/or insulin was metformin (78.4\%) [23]. Thus, it seems to suggest that some level of clinical inertia, where physicians might be slow in responding to the clinical parameters. Indeed, a lack of achieving glycemic control might also be explained by missing of the right drug therapy, although $26.1 \%$ of participants were receiving two or more antidiabetic agents in their recent visit. This allows in evaluating the effect of different characteristics and medications and to make the necessary regimen change and dose adjustment to achieve the anticipated goals of therapy.

Results obtained from multivariable analysis indicated that differences between participants due to factors associated with poor glycemic control were being female, greater BMI $\left(>30 \mathrm{~kg} / \mathrm{m}^{2}\right)$ and low to medium medication adherence. Moreover, females with T2D were more likely to have poor glycemic control. This was consistent with the study conducted in Ethiopia [21] and abroad [24]. In fact, in our study, a low dose of antidiabetics that need to be titrated their dose was higher in female participants than male participants $(67.2 \%$ versus $23.8 \%, \mathrm{p}=0.03)$. This is agreed with the study found that women had needed a higher insulin dose $/ \mathrm{kg}$ than men [25]. Hence, we recommend that prescribers need to be aware of the need to titrate insulin dosing and intensify the treatment pattern, principally in women participants with poor glycemic control as they are more obese and accumulated bad cholesterol than men with diabetes, to achieve the intended glycemic target. In the present study, the reason could be due to: (1) Ethiopian female might not attend their follow up therapy as needed as male due to additional workload in home and thus be less likely to follow their drug therapy attentively (2) less adherent to their lifestyle modification therapies, like regular physical activity. In fact, this could be related with obesity, $76 \%$ of participants with $>30 \mathrm{~kg} / \mathrm{m}^{2}$ BMI was found among female participants of this study. A good explanation for such issues was supported by WHO [4] and Lester [26], which reported more physical inactivity, obesity and overweight were observed in Ethiopian females than males. This is in agreement with three different studies, implies fewer women were achieved their glycemic target compared to men [25, 27, 28]. Gender difference influences the liability to diabetes therapies; negatively affect accessing health services and amplify the impact of diabetes on them. Thus, many women in the world had poor accesses to treatment, care and education [29]. Lifestyle modification is an important non-pharmacological therapy in reducing risks for patients with diabetes. In this study, we found that the odds of participants with poor glycemic control were also increased with BMI ( $\geq 30 \mathrm{~kg} /$ $\mathrm{m}^{2}$ ). In line with studies reported in Tehran as waist circumference was a predictor for poor glycemic control in female patients with T2D [30] and the percentage of patients with poor glycemic control increased as BMI increases [22].

In line with a study carried out by Kassahun et al. [18], in our study, poor medication adherence was also found as an important predictor of poor glycemic control.. This could be an indicator, in which patients might have poor knowledge about their illness, medications, and/ or poor provision of counseling service. These outlooks are questionable, whether health care providers are not doing what was needed to support their patients in creating awareness their illness and prescribed medications or patients' related factors. This study was highlighted that poor adherence is an important factor for poor glycemic control. However, medication adherence should not be supposed as the patient's problem alone. It might due to frustration to agree on the prescription entirely with the patient and/or failure to provide continuous support that the patient needs once the drug has been dispensed. Hence, need to establish patients' perspective in ensuring and inspiring to discuss the aim of their drug therapy to resolve such problems related to medication adherence.

\section{Conclusions}

More than two-thirds of the study participants had poor glycemic control which is far below the recommended standards. Being female gender, obese (BMI $>30 \mathrm{~kg} / \mathrm{m}^{2}$ ) and poor medication adherence was predictors for poor glycemic control. Thus, seems to emphasize the need for a modification in the approach and strategies in diabetes care in achieving the intended glycemic target. 


\section{Limitations of the study}

The inherent nature of cross-sectional retrospective study design that does not show a temporal association could be a limitation. Another limitation was FBG measurements; obtained from medical records that may be subjected to measurement errors could be lead to underestimated or overestimated. However, effort was made to overcome this issue by taking the mean average of the last three consecutive visits of FBG measurements.
Funding

Not applicable.

\section{Publisher's Note}

Springer Nature remains neutral with regard to jurisdictional claims in published maps and institutional affiliations.

Received: 11 March 2019 Accepted: 1 April 2019

Published online: 04 April 2019

\section{References}

1. World Health Organization. Definition and diagnosis of diabetes mellitus and intermediate hyperglycemia: report of a WHO/IDF consultation. Geneva: World Health Organization; 2006.

\section{Additional file}

Additional file 1. Medication profiles among patients with T2D on follow up at diabetes center, Ethiopia, 2018.

\section{Abbreviations}

ADA: American Diabetes Association; ADEs: adverse drug events; CVD: cardio vascular disease; eGFR: estimated glomerular filtration rate; FBG: fasting blood glucose; IDF: International Diabetes Federation; LLAs: lipid-lowering agents; OGLD: oral glucose-lowering drugs; SMBG: self-monitoring of blood glucose; TASH: Tikur Anbessa Specialized Hospital; WHO: World Health Organization.

\section{Authors' contributions}

GTD was made substantial contributions to the conception, design of the work, methodology, analysis, data interpretation and wrote the final manuscript. AG, YLN, GG, GW and DB had equally contributed to analysis and interpretation of the data. WS, HY and MA have made substantial contribution in reviewing overall the study in analysis, interpretation of data, have drafted the manuscript and substantively revised the work. All authors reviewed the submitted version of the manuscript. All authors read and approved the final manuscript.

\section{Author details \\ 1 School of Pharmacy, Aksum University, Po.Box: 298, Aksum, Ethiopia. ${ }^{2}$ School of Public Health, Adigrat University, Adigrat, Ethiopia. ${ }^{3}$ School of Medicine, Addis Ababa University, Addis Ababa, Ethiopia. ${ }^{4}$ School of Pharmacy, Addis Ababa University, Addis Ababa, Ethiopia. ${ }^{5}$ School of Pharmacy, Mekelle University, Mekelle, Ethiopia. ${ }^{6}$ School of Nursing, Aksum University, Aksum, Ethiopia.}

\section{Acknowledgements}

Authors would like to acknowledge individuals who involved in data collection and participants for their dedicated work and valuable input.

\section{Competing interests}

The authors declare that they have no competing interests.

\section{Availability of data and materials}

The datasets used and/or analysed during the current study are available from the corresponding author on reasonable request.

\section{Consent for publication}

Not applicable.

\section{Ethics approval and consent to participate}

The study was approved by the Institutional Review Board of Addis Ababa University, College of Health Sciences, and subsequent permission was obtained from the Endocrine and metabolism clinic of the hospital. The methods were carried out in accordance with the relevant guidelines and regulations. Written informed consent was obtained from all participants. Participants were informed about their rights to refuse or withdraw, and confidentiality of the individual information obtained.
2. American Diabetes Association. Classification and diagnosis of diabetes: standards of medical care in diabetes_-2018. ADA Diabetes Care J Clin Appl Res Educ. 2018;41(Supplement 1):S13-27.

3. International Diabetes Federation. IDF diabetes atlas. 8th ed. Brussels: IDF; 2017.

4. World Health Organization. Diabetes country profiles. Geneva: WHO; 2016.

5. Bommer C, Heesemann E, Sagalova V, et al. The global economic burden of diabetes in adults aged 20-79 years: a cost-of-illness study. Lancet Diabetes Endocrinol. 2017;5(6):423-30.

6. Imran SA, Agarwal G, Bajaj HS, Ross S. Targets for glycemic control. Can J Diabetes. 2018;42:S42-6.

7. Koro CE, Bowlin SJ, Bourgeois N, Fedder DO. Glycemic control from 1988 to 2000 among US adults diagnosed with type 2 diabetes: a preliminary report. Diabetes Care. 2004;27(1):17-20.

8. International Diabetes Federation. Clinical practice recommendations for managing type 2 diabetes in primary care. Brussels: IDF; 2017. ISBN 978-2-930229-85-0.

9. Adham M, Froelicher ES, Batieha A, Ajlouni K. Glycaemic control and its associated factors in type 2 diabetic patients in Amman, Jordan. East Mediterr Health J. 2010;16(7):732.

10. Al-Eitan LN, Nassar AM, Saadeh NA, Almomani BA. Evaluation of glycemic control, lifestyle and clinical characteristics in patients with type 2 diabetes treated at King Abdullah University Hospital in Jordan. Can J Diabetes. 2016;40(6):496-502.

11. Ali I, Khan JZ, Khan AU, Ullah I, Ahmad F. Pharmacotherapy evaluation of diabetic patients in ward of general medicine, northwest general hospital \& research centre, a case study from Khyber Pakhtunkhwa, Pakistan. Pharmacol Online. 2015;1:104-8.

12. Nigatu T. Epidemiology, complications and management of diabetes in Ethiopia: a systematic review. J Diabetes. 2012;4(2):174-80.

13. Donaghue KC, Chiarelli F, Trotta D, Allgrove J, Dahl-Jorgensen K. Microvascular and macrovascular complications associated with diabetes in children and adolescents. Pediatr Diabetes. 2009;10(s12):195-203.

14. Khattab M, Khader YS, Al-Khawaldeh A, Ajlouni K. Factors associated with poor glycemic control among patients with type 2 diabetes. J Diabetes Complicat. 2010;24(2):84-9.

15. Sattar AN. The adequateness of glycemic control in type 2 diabetes mellitus. Med J Babylon. 2015;12(4):1129-36.

16. Kautzky-Willer A, Harreiter J, Pacini G. Sex and gender differences in risk, pathophysiology and complications of type 2 diabetes mellitus. Endocr Rev. 2016;37(3):278-316.

17. EPIDATAM. EpiData Association, att. Jens M.Lauritsen. Enghavevej 34 DK5230 Odense M, Denmark, Europe, 2006.

18. Kassahun T, Eshetie T, Gesesew H. Factors associated with glycemic control among adult patients with type 2 diabetes mellitus: a cross sectional survey in Ethiopia. BMC Res Notes. 2016;9(1):1.

19. Hailu E, Mariam WH, Belachew T, Birhanu Z. Self-care practice and glycaemic control amongst adults with diabetes at the Jimma University Specialized Hospital in south-west Ethiopia: a cross-sectional study. Afr J Prim Health Care Fam Med. 2012;4(1):1-6.

20. Angamo MT, Melese BH, Ayen WY. Determinants of glycemic control among insulin treated diabetic patients in Southwest Ethiopia: hospital based cross sectional study. PLOS ONE. 2013;8(4):e61759. 
21. Yigazu DM, Desse TA. Glycemic control and associated factors among type 2 diabetic patients at Shanan Gibe Hospital, Southwest Ethiopia. BMC Res Notes. 2017;10:597.

22. Weng W, Tian Y, Kimball ES, et al. Treatment patterns and clinical characteristics of patients with type 2 diabetes mellitus according to body mass index: findings from an electronic medical records database. BMJ Open Diabetes Res Care. 2017:5(1):e000382.

23. Pantalone KM, Hobbs TM, Wells BJ, et al. Clinical characteristics, complications, comorbidities and treatment patterns among patients with type 2 diabetes mellitus in a large integrated health system. BMJ Open Diabetes Res Care. 2015;3(1):e000093.

24. Claydon-Platt K, Manias E, Dunning T. Medication-related problems occurring in people with diabetes during an admission to an adult teaching hospital: a retrospective cohort study. Diabetes Res Clin Pract. 2012;97(2):223-30.

25. Kautzky-Willer A, Kosi L, Lin J, Mihaljevic R. Gender-based differences in glycaemic control and hypoglycaemia prevalence in patients with type 2 diabetes: results from patient-level pooled data of six randomized controlled trials. Diabetes Obes Metab. 2015;17(6):533-40. https://doi. org/10.1111/dom.12449.

26. Lester FT. The clinical pattern of diabetes mellitus in Ethiopians. Diabetes Care. 1984;7:6-11.

27. Asfaw AA, Mamo NM, Anshabo AT, Hawaze S. Assessment of type II diabetes mellitus drug therapy in diabetes clinic of a tertiary care teaching hospital in Addis Ababa. Arch Pharm Pract. 2014;5(3):113.

28. Yigazu DM, Desse TA. Glycemic control and associated factors among type 2 diabetic patients at Shanan Gibe Hospital, Southwest Ethiopia. BMC Res Notes. 2017;10(1):597.

29. International Diabetes Federation. IDF-WDD (world Diabetes Day), 2017 event. Secondary International Diabetes Federation. IDF-WDD (world Diabetes Day), 2017 event December 2, 2017. 2017. http://worlddiabe tesday.org/about-wdd/wdd-2017/wdd-2017-event.html. Accessed 21 Sept 2018.

30. Ghazanfari Z, Niknami S, Ghofranipour F, Larijani B, Agha-Alinejad H, Montazeri A. Determinants of glycemic control in female diabetic patients: a study from Iran. Lipids Health Dis. 2010;9(1):83
Ready to submit your research? Choose BMC and benefit from:

- fast, convenient online submission

- thorough peer review by experienced researchers in your field

- rapid publication on acceptance

- support for research data, including large and complex data types

- gold Open Access which fosters wider collaboration and increased citations

- maximum visibility for your research: over $100 \mathrm{M}$ website views per year

At BMC, research is always in progress.

Learn more biomedcentral.com/submissions 